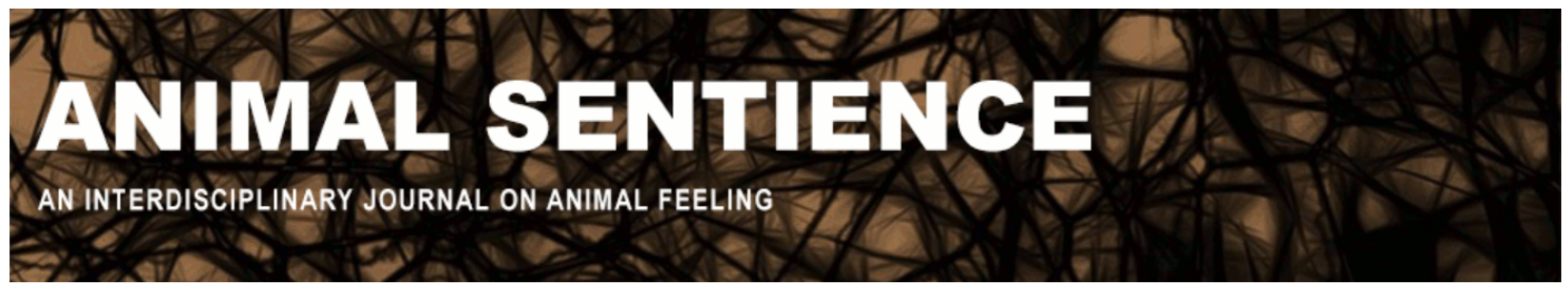

Howard, Scarlett R. and Dyer, Adrian G. (2020) How to engage public support to protect overlooked species. Animal Sentience 27(25)

DOI: $10.51291 / 2377-7478.1569$

Date of submission: 2020-03-20

Date of acceptance: 2020-04-01

(c)

This article has appeared in the journal Animal

Sentience, a peer-reviewed journal on animal

cognition and feeling. It has been made open access,

free for all, by WellBeing International and deposited

in the WBI Studies Repository. For more information,

please contact

wbisr-info@wellbeingintl.org.

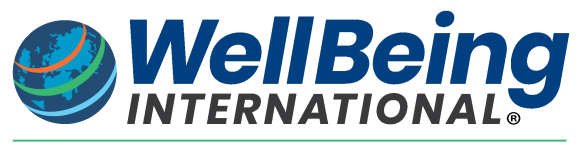

SOLUTIONS FOR PEOPLE, ANIMALS AND ENVIRONMENT 


\title{
How to engage public support to protect overlooked species
}

Commentary on Treves et al. on Just Preservation

\author{
Scarlett R. Howard \\ School of Life and Environmental Sciences, Deakin University \\ Adrian G. Dyer \\ School of Media and Communication, RMIT University
}

\begin{abstract}
Treves et al. (2019) propose a non-anthropocentric approach to conservation biology for the 'just preservation' of non-humans. Some of our current ways of ranking conservation efforts based on benefits to humans are indeed critically flawed, but we doubt that a completely nonanthropocentric approach is possible at this time. We propose a way to generate public support for those non-human species that may otherwise be overlooked in policy-making and conservation efforts.
\end{abstract}

Scarlett R. Howard is a postdoctoral research fellow at Deakin University with an interest in science communication. Her research explores conceptual learning, neurobiology, and visual perception in honeybees as well as insect diversity, pollinator preferences, and plant-pollinator interactions. Website

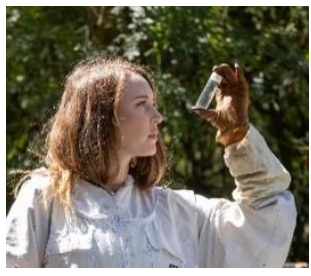

Adrian G. Dyer, Research Fellow at RMIT University and Monash University, studies comparative animal cognition and visual ecology as well as digital modelling for resource management. Website

Treves et al. (2019) suggest an interesting and ambitious goal for the 'just preservation' of nonhumans. We agree that conservation should be far less anthropocentric but we are unsure of how achievable the goals of the target article are without support from the public and thus pressure on governments and policy makers to act with a non-anthropocentric agenda. Other commentators have also noted that Treves et al.'s approach faces challenges, suggesting that is underdeveloped (Franks et al. 2020) and has cultural oversights (Bergstrom 2019). Species are not all considered equal today, nor are they likely to be considered equal in the court proceedings that Treves et al. envision based on past and current conservation efforts (Small 2011; Trimble and Van Aarde 2010; Veríssimo et al. 2017). Moreover, a legal approach is likely to run into questions about jurisdiction and who pays the legal costs. As other commentaries have suggested, disentangling human interests from conservation may not be possible and may even cause more problems (Batavia 2020). We would like to suggest an alternative that combines nonanthropocentric and anthropocentric approaches to generate public pressure on governments and policy makers to protect insect species. 
Public support for conserving and protecting specific species usually concerns the 'cute and cuddly' or 'beautiful but deadly' animals, (e.g., pandas, penguins, tigers, polar bears, gorillas, whales, etc.) (Small 2011; Trimble and Van Aarde 2010; Veríssimo et al. 2017). Less attractive or lower-profile species are not usually considered worth saving (Small 2011; Trimble and Van Aarde 2010; Veríssimo et al. 2017). As researchers working extensively with bees, we have experience with a social media strategy for raising public awareness by combining, with the (anthropocentric) value of an insect species to humans, the species' own individual (non-anthropocentric) value (Dyer et al. in press).

In response to a 2019 National Geographic survey asking "If you could dedicate your life to saving one species, which would you choose?" (Main 2019), most people picked "the bee." There are many bee species; some are in critical danger of extinction (e.g., seven surviving yellowfaced bees in Hawaii; Fish and Wildlife Service, 2016) whereas the threat to other bee species is currently low. How did an insect become one of the most popular animals to protect? And how can we promote other, less popular species if we are to reach the goals of Treves et al.?

In 2007, beekeepers reported the mysterious and rapid decline of managed honeybee hives in the US and worldwide (Johnson 2007). There was significant concern and demand for action to solve the problems of colony collapse disorder (CCD), the varroa mite (Varroa destructor), and pesticides (Dicks 2013). Bees became the poster child for insect declines (Forister et al. 2019; Hallmann et al. 2017; Wagner 2019). The public and the media have since rallied to support their conservation and bees have become popular insect species (Sumner et al. 2018), especially honeybees (Apis mellifera) (Smith and Saunders 2016). This media attention has entered popular culture through books (Kearney 2019; Kearney and Holliday 2019) and film (e.g., Bee Movie). Although the honeybee species is not at risk of extinction, this attention has made the public want to protect pollinators and their environments. With the appropriate communication to the public, other overlooked and less popular species could be promoted in a similar way, making their preservation easier to achieve.

Building on the popularity of honeybees in the media (Smith and Saunders 2016), our team aimed to raise awareness of the intelligence of bees following experiments and publications between 2016 and 2019. Our team studied the numerical abilities of bees and actively disseminated the findings to the public to raise the profile of bees from 'just insects' who provide services to humans (e.g., honey, pollination, food production, wax) to intelligent beings with the ability to perform complex tasks, including numerical cognition. Bees are already known to display emotions (Bateson et al. 2011; Schlüns et al. 2017) and individuality (Dyer 2012; Dyer et al. 2019b; Howard et al. 2019a; Howard et al. 2019b). Klein and Barron (2016) have accordingly inferred that insects are conscious. This suggests that they should be seriously considered in conservation and preservation efforts, as suggested by other commentators (Correia Caeiro 2020; Paez 2020).

Bees can understand the concept of zero (Howard et al. 2018a; Howard et al. 2018b), quantify numerical values (Howard et al. 2018b; Howard et al. 2019c), add and subtract (Howard et al. 2019a; Howard et al. 2019b), represent numerosities symbolically (Howard et al. 2019d), and compare and value numbers (Howard et al. 2018b; Howard et al. 2019c). We formed findings into narratives to disseminate to the public, wrote a series of articles for The Conversation, performed interviews reaching more than 150 news outlets (as estimated by the R\&I Team at RMIT University), thus promoting the intelligence of a small insect brain (Chittka and Niven 2009). Our publication in Science (Howard et al. 2018b) reached over 100 million people and our 
subsequent publication in Science Advances (Howard et al. 2019b) reached over 700 million people (Dyer et al. in press; White 2020).

We were able to present the honeybee in a new light, not only as a species useful for what it could provide to humans (Gallai et al. 2009), but also for its intelligence and individuality in problem solving (Dyer et al. 2019b; Howard et al. 2019a). Spontaneous feedback from the general public ranged from school-aged children through to retired people, all fascinated by the evidence of what bees can do, and how we can work as a community to look after them.

If an insect species can manage to create enough public interest to induce changes in policy and law (e.g., banning of neonicotinoids in Europe, Dicks 2013; increases in city green space), a similar strategy could increase the profile of other overlooked animal and plant species. Synergistic win-win solutions are more likely to promote long-term success than legislative action that disregards how humans and non-humans co-exist in a complex world. Applying Thaler and Sunstein's (2008) "nudge theory" to seeking beneficial and cost-effective outcomes may be a promising alternative pathway to protecting animals. In the current climate, demanding that all living things be treated as equal to humans would be difficult to promote convincingly; untangling the preservation of all life and nature from the anthropocentric focus of protecting human rights would be challenging. We suggest instead an approach that inspires the public to seek changes in policy, preservation, and the future of our environment.

\section{References}

Barron AB, Klein C (2016) What insects can tell us about the origins of consciousness. Proceedings of the National Academy of Sciences 113(18):4900-4908.

Batavia C (2020) Is anthropocentrism really the problem? Animal Sentience 27(20).

Bateson M, Desire S, Gartside SE, Wright GA (2011) Agitated honeybees exhibit pessimistic cognitive biases. Current Biology 21(12):1070-1073.

Bergstrom BJ (2019) Just reductionism: In defense of holistic conservation. Animal Sentience 27(8).

Chittka L, Niven J (2009) Are bigger brains better? Current Biology 19(21):R995-R1008.

Correia Caeiro C (2020) Comparative cognition and nonhuman individuality. Animal Sentience 27(16).

Dicks L (2013) Bees, lies and evidence-based policy. Nature 494:283-283

Dyer A, Garcia J, Howard S (2019a) Bees can learn higher numbers than we thought-if we train them the right way. Education News 68(4):48-49.

Dyer A, Howard SR, Garcia JE (In Press) Balancing research excellence and media impact: A multistage approach. The Royal Society of NSW.

Dyer AG (2012) The mysterious cognitive abilities of bees: Why models of visual processing need to consider experience and individual differences in animal performance. The Journal of Experimental Biology 215:387-395.

Dyer AG, Garcia JE, Howard SR, Avarguès-Weber A, Greentree AD (2019b) Common principles in learning from bees through to humans: Individual differences set a basis for learning theory and implementations into Al. Video Journal of Education and Pedagogy. 
Fish and Wildlife Service (2016) Endangered and threatened wildlife and plants; Endangered status for 49 species from the Hawaiian Islands. Federal Register 81(190):67786-67860.

Forister ML, Pelton EM, Black SH (2019) Declines in insect abundance and diversity: We know enough to act now. Conservation Science and Practice 1(8):e80.

Franks B, Webb C, Gagliano M, Smuts B (2020) Conventional science will not do justice to nonhuman interests: A fresh approach is required. Animal Sentience 27(17).

Gallai N, Salles J-M, Settele J, Vaissière BE (2009) Economic valuation of the vulnerability of world agriculture confronted with pollinator decline. Ecological Economics 68(3):810-821.

Hallmann CA, Sorg M, Jongejans E, Siepel H, Hofland N, Schwan H, Stenmans W, Müller A, Sumser H, Hörren T, Goulson D, de Kroon H (2017) More than 75 percent decline over 27 years in total flying insect biomass in protected areas. PLoS One 12(10):e0185809.

Howard S, Garcia J, Dyer A (2018a) Chasing the meaning of zero. Australasian Science 39(6):2021.

Howard SR, Avarguès-Weber A, Garcia JE, Greentree AD, Dyer AG (2018b) Numerical ordering of zero in honey bees. Science 360(6393):1124-1126.

Howard SR, Avarguès-Weber A, Garcia JE, Greentree AD, Dyer AG (2019a) Achieving arithmetic learning in honeybees and examining how individuals learn. Communicative \& Integrative Biology 12(1):166-170.

Howard SR, Avarguès-Weber A, Garcia JE, Greentree AD, Dyer AG (2019b) Numerical cognition in honeybees enables addition and subtraction. Science Advances 5(2):eaav0961.

Howard SR, Avarguès-Weber A, Garcia JE, Greentree AD, Dyer AG (2019c) Surpassing the subitizing threshold: appetitive-aversive conditioning improves discrimination of numerosities in honeybees. Journal of Experimental Biology 222:jeb205658.

Howard SR, Avarguès-Weber A, Garcia JE, Greentree AD, Dyer AG (2019d) Symbolic representation of numerosity by honeybees (Apis mellifera): Matching characters to small quantities. Proceedings of the Royal Society B: Biological Sciences 286(1904): 20190238.

Johnson R (2007) Recent honey bee colony declines. CRS Report for Congress.

Kearney H (2019) Queen spotting: Meet the remarkable queen bee and discover the drama at the heart of the hive. Storey Publishing, LLC.

Kearney H, Holliday A (2019) The little book of bees: An illustrated guide to the extraordinary lives of bees. HarperCollins Publishers.

Klein C, Barron, AB (2016) Insects have the capacity for subjective experience. Animal Sentience 9(1).

Main D (2019) We asked readers which species they'd save-here are the top responses. National Geographic.

Paez E (2020) Preserving nature for the benefit of all sentient individuals. Animal Sentience 27(18).

Schlüns H, Welling H, Federici JR, Lewejohann L (2017) The glass is not yet half empty: Agitation but not Varroa treatment causes cognitive bias in honey bees. Animal Cognition 20:233-241.

Small E (2011) The new Noah's Ark: Beautiful and useful species only. Part 1. Biodiversity conservation issues and priorities. Biodiversity 12:232-247.

Smith TJ, Saunders ME (2016) Honey bees: The queens of mass media, despite minority rule among insect pollinators. Insect Conservation and Diversity 9:384-390. 
Sumner S, Law G, Cini A (2018) Why we love bees and hate wasps. Ecological Entomology 43:836-845.

Thaler RH, Sunstein CR (2008) Nudge: Improving decisions about health, wealth, and happiness. Yale University Press.

Treves A, Santiago-Ávila FJ, Lynn WS (2019) Just preservation. Animal Sentience 27(1).

Trimble MJ, Van Aarde RJ (2010) Species inequality in scientific study. Conservation Biology 24:886-890.

Veríssimo D, Vaughan G, Ridout M, Waterman C, MacMillan D, Smith RJ (2017) Increased conservation marketing effort has major fundraising benefits for even the least popular species. Biological Conservation 211:95-101.

Wagner DL (2019) Insect declines in the Anthropocene. Annual Review of Entomology 65:457480.

White S (2020) Three studies are showing bees' amazing math abilities. Discover. 


\section{Call for Papers}

Special Issue of the Lournal of Consciousness Studies

Plant Sentience: Theoretical and Empirical Issues

Guest Editors: Vicente Raja (Rotman Institute of Philosophy, Western University) Miguel Segundo-Ortin (School of Liberal Arts, University of Wollongong)

In this special issue, we address the issue of plant sentience/consciousness from different disciplines that combine both theoretical and empirical perspectives. Some of the questions to be addressed in the special issue include the following:

- Plants exhibit interesting behaviors; does this entail that they are conscious to some extent?

- What are the requirements for a living organism to be conscious? Do plants meet these requirements?

- What does the possibility of plant sentience/consciousness entail for the study of the evolution of consciousness?

- Is it just a categorical mistake to attribute consciousness to plants?

- Can we talk about different levels or degrees of consciousness?

\section{How to submit?}

Deadline: June 1 1st $^{\text {, } 2020}$

Please submit your papers (max. 9000 words including footnotes, references, abstract, etc.) to vgalian@uwo.ca with subject "Paper Special Issue JCS".

For more information, including bibliography and more detailed descriptions of the topics and questions to be addressed in the papers submitted to the special issue, please contact the guest editors at vgalian@uwo.ca (Vicente) or ms0693@uowmail.edu.au (Miguel). 